\title{
Comparison of the Dose Load in Different Procedures for Personnel Working with Angiographic X-Ray Equipment
}

\author{
Natasha Ivanova1, Javor Ivanov² \\ ${ }^{1}$ Medical University “Prof. Dr. Paraskev Stoyanov”, Varna, Bulgaria \\ ${ }^{2} S$ \& T Bulgaria EOOD, Sofia, Bulgaria \\ Email: natasha_i@abv.bg
}

How to cite this paper: Ivanova, N. and Ivanov, J. (2021) Comparison of the Dose Load in Different Procedures for Personnel Working with Angiographic X-Ray Equipment. Open Access Library Journal, 8: e7412.

https://doi.org/10.4236/oalib.1107412

Received: April 12, 2021

Accepted: May 3, 2021

Published: May 6, 2021

Copyright $\odot 2021$ by author(s) and Open Access Library Inc.

This work is licensed under the Creative Commons Attribution International License (CC BY 4.0).

http://creativecommons.org/licenses/by/4.0/

\begin{abstract}
The main goal of the article is to compare the effective radiation doses received by the leading interventional cardiologist during the angiographic procedures. A comparison is done between the dose load during three procedures-LAD-stenting, LCx-stenting and RCA-stenting. An angiographic X-ray system Philips Allura Xper FD10 (with G-arm) was used for this study. The dose obtained was measured with an X-ray-Gamma Dosimeter 27091. The dose measurements were made for the respective projections of each angiographic procedure and for the operation modes of the equipment used during the respective procedure at three measurement points on the operator's body-head, gonads and feet. The results obtained from the calculations, based on the measured dose values, show maximum dose load in the procedure that uses the radiographic mode of operation for the longest time, namely RCA-stenting.
\end{abstract}

\section{Subject Areas}

Radiology \& Medical Imaging

\section{Keywords}

G-Arm Type Angiographic X-Ray System, Dose Load, Interventional Cardiology, Cardiology Hospital

\section{Introduction}

\subsection{Purpose of the Study}

The purpose of the study was based on the performed dosimetric measurements 
to make evaluation of the dose load, received by an interventional cardiologist from to the scattered $\mathrm{X}$-ray radiation for different angiographic procedures during work with the angiographic system Philips Allura Xper FD10.

\subsection{Motivation}

The specific angiographic procedures require use of different projections where the X-ray tube is pointed at a specific angle to the patient table and to the main cardiologist, performing the procedure. During each procedure several different projections are used. For each projection a specific dose load is received by the main interventional cardiologist. In some projections, both fluorography and radiography modes of operation of the X-ray equipment are used and the exposure time for the respective projection and operation mode is different as well. Thus, the total dose load for each specific angiographic procedure is different. All these circumstances inspired us to perform calculations based on the data collected from the measurements and to estimate the dose load that the main operator receives during each specific procedure [1].

\section{Materials and methods}

\section{Dosimetric measurement}

We measured the dose received by a cardiologist performing an angiographic procedure. Measurements were performed for all of the 9 most commonly used G-arm projections. Each measurement was made at three points on the cardiologist's body: head, gonads and feet and for three different table positions: zero height (according to the default system adjustment), lowest possible position for the respective projection and highest possible position.

The practical measurements were made in the Specialized Hospital for Active Treatment in Cardiology (SBALK) Varna, in the Department of Invasive Cardiology.

Research team (participants in the dosimetric measurements):

- The first author of this article-a representative of the Medical University and processing the received data;

- Service engineer maintaining the X-ray equipment: the measurements were carried out under the direct and continuous control of the service engineer of the X-ray system;

- Medical physicist-Head of the Radiation Protection Department at the Regional Health Inspectorate, Varna, working with the measuring device;

- Three interventional cardiologists from the Cardiac Hospital who provided information and instructions on the interventional procedures and projections used during the measurements [1].

The study was performed in a procedure room of an angiographic X-ray system with G-arm Philips Allura Xper FD10 (Figure 1). For the dosimetric measurement was used an X-Ray-Gamma-Dosimeter RGD 27091 (Figure 2) [2] A 19-liter water bottle was used as phantom (Figure 3). 
The dose measurements were performed for three different patient table positions-zero height (default position set by the factory), highest and lowest position for the respective procedure for the three measurement points- "Head", "Gonads", "Feet". Figure 1 shows the positions of the three measurement points.

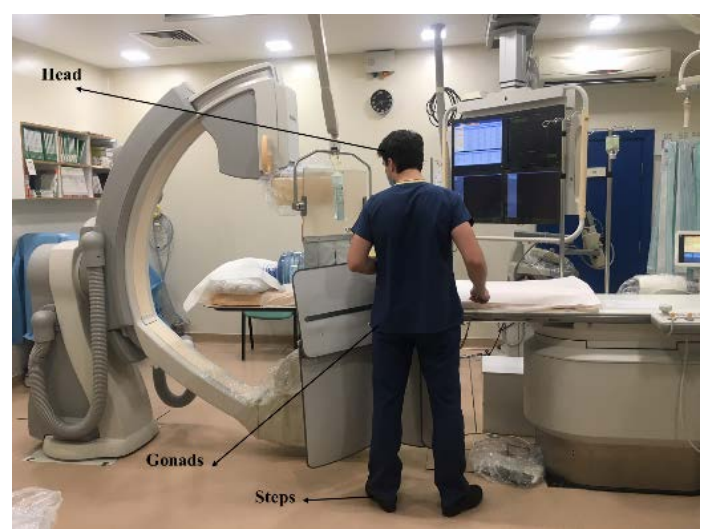

Figure 1. Angiographic X-ray system Philips Allura Xper FD10 and Position of cardiologist in relation to patient table, G-arm, radiation protection shield. Measuring points: head, gonads and steps.

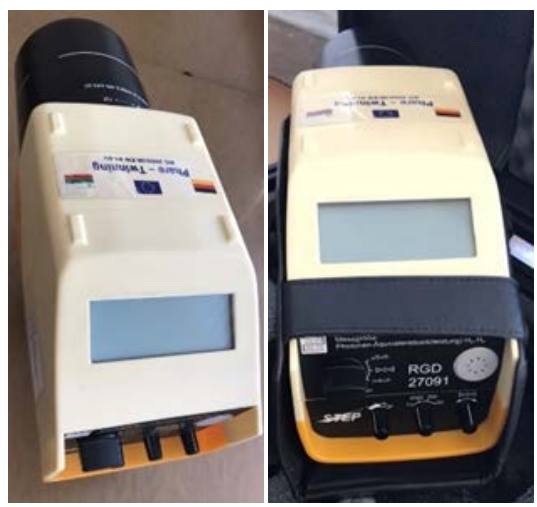

Figure 2. X-Ray-Gamma-Dosimeter RGD 27091.

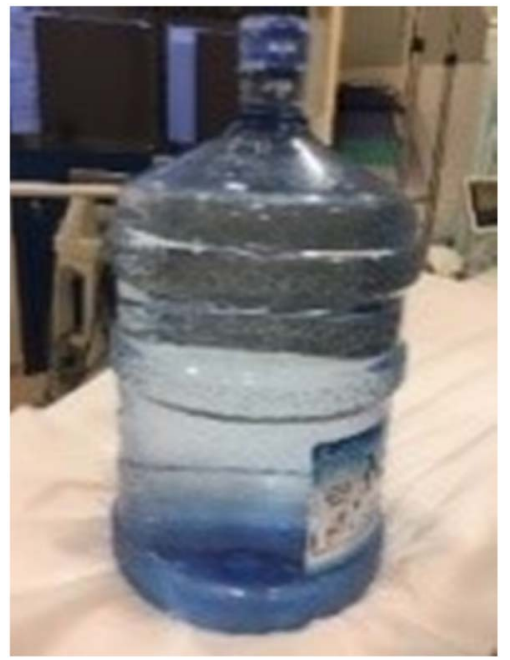

Figure 3. Phantom. 
Dose evaluation of the first operator was performed for three angiographic procedures: LAD-stenting, LCx-stenting and RCA-stenting.

1) LAD-stenting. Following projections are used (Table 1):

Total time for the performed procedure 45 - $90 \mathrm{~min}$.

Total time for the basic projection 30 to 60 minutes: Each of the three mentioned projections can be used as basic projection. The exposure time in pulse fluoroscopy mode for the basic projection is about $10 \mathrm{~min}$. The exposure time in radiography mode for the basic projection is about $2-3 \mathrm{~min}$.

Total time for the other projections-15 to $30 \mathrm{~min}$. The exposure time for these projections in pulse fluoroscopy is about 5 minutes.

\section{2) LCx-stenting-Following projections are used (Table 2):}

Total time for the performed procedure 45 - $90 \mathrm{~min}$.

Basic projection-30 to $60 \mathrm{~min}$. Each of the three mentioned projections can be used as basic projection depending on the procedure. The exposure time in pulse fluoroscopy mode for the basic projection is about $10 \mathrm{~min}$. The exposure time in radiographic mode for the basic projection is about $2-3 \mathrm{~min}$.

Total time for the other projections-15 to $30 \mathrm{~min}$. Exposure time for these projections in fluoroscopy mode is about 5 minutes.

\section{3) RCA-stenting-Following projections are used (Table 3):}

Total time for the performed procedure about $120 \mathrm{~min}$.

First basic projection-LAO 300-about $60 \mathrm{~min}$. Exposure time in pulse fluoroscopy mode about $10 \mathrm{~min}$. The exposure time in radiography mode is about 2 - 3 minutes.

Second basic projection RAO-cranial 300/300-about $30 \mathrm{~min}$. The exposure Table 1. Projections used in LAD-stenting procedure.

\begin{tabular}{cc}
\hline AP & $0^{\circ} / 0^{\circ}$ \\
RAO-cranial & $30^{\circ} / 30^{\circ}$ \\
LAO-cranial & $30^{\circ} / 30^{\circ}$ \\
Cranial & $30^{\circ}$ \\
\hline
\end{tabular}

Table 2. Projections used in LCx-stenting procedure.

\begin{tabular}{cc}
\hline AP & $0^{\circ} / 0^{\circ}$ \\
RAO-caudal & $30^{\circ} / 15^{\circ}$ \\
LAO-caudal & $30^{\circ} / 30^{\circ}$ \\
Cranial & $30^{\circ}$ \\
\hline
\end{tabular}

Table 3. Projections used in RCA-stenting procedure.

\begin{tabular}{cc}
\hline AP & $0^{\circ} / 0^{\circ}$ \\
RAO-cranial & $30^{\circ} / 30^{\circ}$ \\
LAO-cranial & $30^{\circ} / 30^{\circ}$ \\
Cranial & $30^{\circ}$ \\
\hline
\end{tabular}


time in pulse fluoroscopy mode is about 5 minutes. The exposure time in radiography mode is about $1 \mathrm{~min}$.

Second basic projection-Cranial 300-about $30 \mathrm{~min}$. The exposure time in pulse fluoroscopy mode is about 5 minutes. The exposure time in radiography mode is about $1 \mathrm{~min}$.

The calculations are done for each of the projections as basic projection and for the remaining two projections as non-basic projections [1].

\section{Results}

Diagrams 1-3 shows comparison of the received dose load for the whole procedure for each of the three performed procedures, for the three patient table positions and at the three measurement points. For each of the procedures, the dose received in fluoroscopic and radiographic mode of operation is calculated. The calculations are performed for 3 minutes radiographic mode for the basic projection for the procedures $\mathrm{LAD}$-stenting and $\mathrm{LCx}$-stenting.

In Tables 4-6 are given statistics comparing the doses obtained at the three measuring points, at the three table positions for the three procedures.

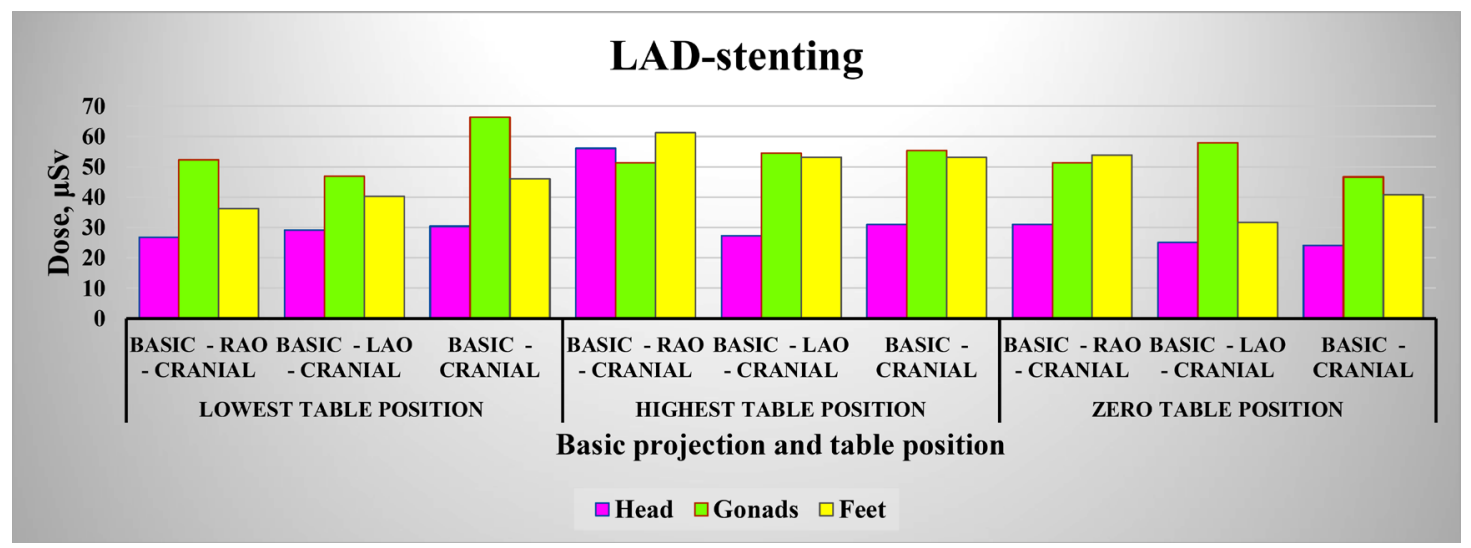

Diagram 1. Comparison of the dose received by the first operator in a procedure LAD-stenting at the three positions of the table at the three measured points at 3 minutes radiography.

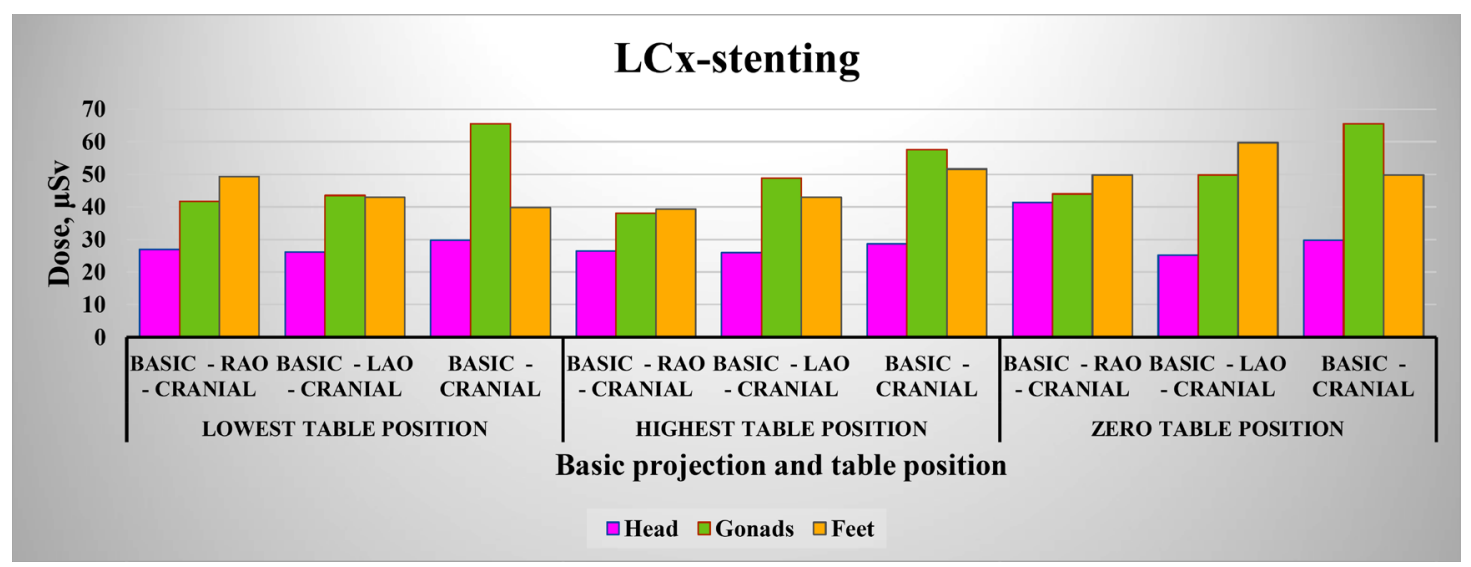

Diagram 2. Comparison of the dose received by the first operator in a procedure RCx-stenting at the three positions of the table at the three measured points at 3 minutes radiography. 


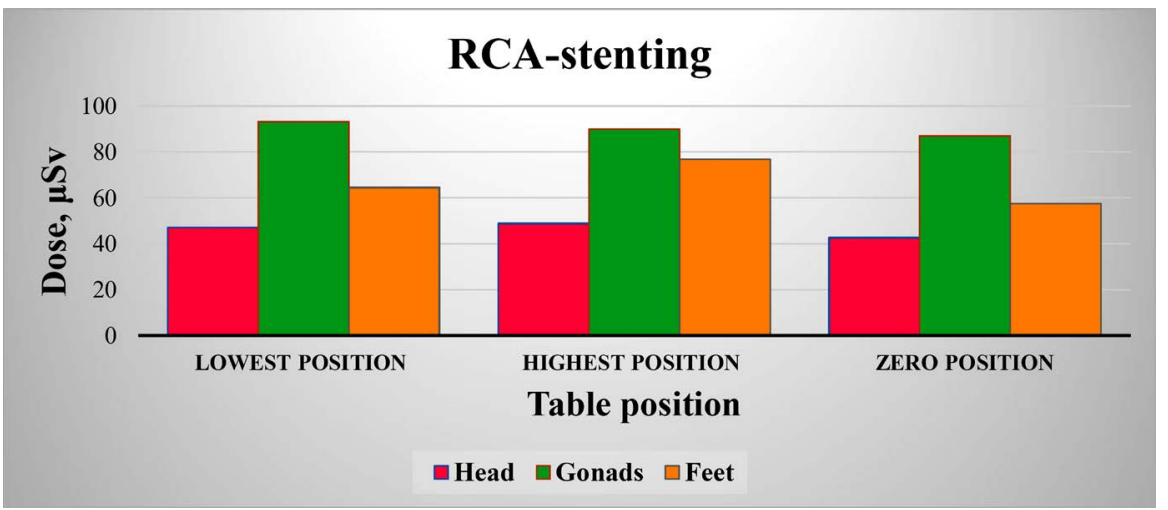

Diagram 3. Comparison of the dose received by the first operator in a procedure RCAstenting at the three positions of the table at the three measured points.

Table 4. Statistics comparing the doses obtained at the three measuring points, without taking into account the position of the table for procedure RCA-stenting.

\begin{tabular}{|c|c|c|c|}
\hline \multicolumn{4}{|c|}{ RCA-stenting } \\
\hline statistical quantities/meas. points & head & gonads & feet \\
\hline Arithmetic average & 46.20 & 90.10 & 66.30 \\
\hline Standard Deviation & 3.42 & 3.15 & 9.73 \\
\hline
\end{tabular}

Table 5. Statistics comparing the doses obtained at the three measuring points at the three table positions of the procedure LAD-stenting.

\begin{tabular}{|c|c|c|c|c|}
\hline \multicolumn{5}{|c|}{ LAD-stenting } \\
\hline Table position & statistical quantities & head & gonads & feet \\
\hline without taking into account & Arithmetic average & 31.19 & 53.59 & 46.25 \\
\hline the table position & Standard Deviation & 9.67 & 6.02 & 9.70 \\
\hline Lowes & Standard Deviation & 1.87 & 10.05 & 4.95 \\
\hline Highest & Standard Deviation & 15.69 & 2.13 & 4.65 \\
\hline Zero & Standard Deviation & 3.66 & 5.65 & 11.16 \\
\hline
\end{tabular}

Table 6. Statistics comparing the doses obtained at the three measuring points at the three table positions of the procedure LCx-stenting.

\begin{tabular}{|c|c|c|c|c|}
\hline \multicolumn{5}{|c|}{ LCx-stenting } \\
\hline Table position & statistical quantities & head & gonads & feet \\
\hline without taking into account & Arithmetic average & 28.89 & 50.51 & 47.24 \\
\hline the table position & Standard Deviation & 4.97 & 10.18 & 6.59 \\
\hline Lowes & Standard Deviation & 1.87 & 13.28 & 4.87 \\
\hline Highest & Standard Deviation & 1.46 & 9.76 & 6.32 \\
\hline Zero & Standard Deviation & 8.36 & 11.17 & 5.72 \\
\hline
\end{tabular}

Comparing the Diagrams 1-3 and Tables 4-6 it can be seen that RCA-stenting procedure shows the highest values of the received dose (Aritmetic averages are 
highest). The received dose is almost the same for all positions in the patient table. (The standard deviation has small and very close values for the measured points "head" and "gonads", the largest—is at the measured point "legs").

Looking at the diagrams and the statistical data for LAD and LCx it becomes clear, that the average values for the different measurement points are comparable. At the points "head" and "gonads" the dose values for the LAD-stenting are higher-there is a difference of about $3 \mu \mathrm{Sv}$. The opposite is true for the point "Feet", but the difference is less than $1 \mu \mathrm{Sv}$. The lowest arithmetic mean and standard deviation are observed for the measurement point "Head". Lower standard deviation is observed in the LCx-stenting. Here, the highest value is for the zero-position of the patient table. The obtained dose values are very close to the arithmetic mean for this point. For LAD stenting, the standard deviation varies significantly: from 1.87 for the lowest position on the patient table to 15.69 for the highest position on the patient table (i.e. the doses received differ significantly). The highest arithmetic mean and standard deviation are observed at the measurement point "Gonads". At this point higher standard deviations are observed for LCx-stenting. Here, the highest value is for the lowest patient table position and the lowest-for the highest table position. For the measurement point "Feet" both the arithmetic mean and the standard deviation are between those for the other two points. For this point, it is not possible to determine definitively which of the two procedures gives a larger standard deviation. The greatest standard deviation is observed in the zero position of the patient table for LAD-stenting.

\section{Discussion}

In the modern world, the use of X-ray equipment for diagnostic and treatment purposes is increasingly affecting our lives. Because of this, safety is a constant concern when using this type of equipment. This was the motivation for our team to focus the study on the dose load of the staff working with X-ray equipment. The other major reason was the interventional cardiologists' interest in knowing the radiation doses they are receiving during the procedures.

The topic of the dose load during invasive cardiac procedures is widely discussed.

The article " $\mathrm{C}$-arm rotation as a method for reducing peak skin dose in interventional cardiology" discusses the topic of changing the dose received from the patient's skin at different positions of the $\mathrm{C}$-arm during cardiac procedures [3].

Patient dose is discussed by V. Sadick, W Reed, et al. in "Impact of biplane versus single-plane imaging on radiation dose, contrast load and procedural time in coronary angioplasty" [4] and by Mavrikou I, Kottou S, et al. in "High patient doses in interventional cardiology due to physicians' negligence: how can they be prevented?" too [5].

In the article " 5 Technologies to Reduce Cath Lab Radiation Exposure" its authors discuss reducing of the staff radiation dose from X-ray angiography and 
long-term back pain due to weight of lead aprons [6].

This article "Radiation exposure and adverse health effects of interventional cardiology staff" discuss the first systematic review of radiation exposure to eyes, thyroid, and hands for Interventional Cardiology (IC) staff [7].

Modern science is creating new tools to estimating and control the dose received. The article "InterCardioRisk: a novel online tool for estimating doses of ionising radiation to occupationally-exposed medical staff and their associated health risks" discuss the application of such an instrument [8].

All of these articles discuss the effective use of the C-arm device in order to reduce as much as possible the dose received by the patient and by the staff working with the equipment.

Our article discusses the dose load, received by the interventional cardiologist during three different cardiological procedures, performed under X-ray control. For all the three procedures sometimes is used radiographic mode of operation of the X-ray equipment and sometimes fluoroscopic mode. Here, we calculated the effective dose for the respective exposure time and at the end we summed the dose load obtained for each of the operation modes for the given procedure. Because the duration of the work in radiographic mode varies from 2 to 3 minutes, we calculated the results for these two extreme durations, namely 2 and $3 \mathrm{mi}-$ nutes radiography. Each of these calculations was made for the three measurement points-head, gonads and feet for all the three positions of the patient table-lowest, highest and zero-position (default factory position) for which the measurement were done. In this article we are gives only the results for 3 minutes.

\section{Conclusions}

Regarding the dose load at the different measurement points, the highest values are observed for the point "gonads", and the lowest for "head" for all three tested procedures. From the obtained results a definite conclusion about the dose load can be given only for the procedure RCA-stenting. In this procedure, the dose load is greatest at the different measurement points and for all positions of the patient table. This can be explained by the longest duration of radiography, which leads to high dose levels.

The dose load in the other two procedures is almost the same with small differences for the different positions of the patient table. It cannot be concluded definitely which one is more dose-loading. Differences in dose load are observed for the different patient table positions. This can be explained with the approximately the same duration of work under X-ray control both in fluoroscopic and radiographic mode of operation.

\section{Acknowledgements}

Special thanks to the three physicians, members of our research team, from the Cardiology Hospital, Varna, Bulgaria: Dr. Ismet Tahsinov, Ph.D. Hrisimir Todorov, Ph.D. Nikolai Aleksandrov, without whose invaluable help our team 
would not have done so well.

Special thanks also to the medical physicist Bistra Manusheva, Head of the Radiation Control Department at the Regional Health Inspectorate, Varna, for the provided equipment for the dosimetric measurements.

And last but not least, special thanks to the editors of the magazine for their help in printing the article.

\section{Conflicts of Interest}

The authors declare no conflicts of interest regarding the publication of this paper.

\section{References}

[1] Ivanova, N. (2020) Angiographic X-Ray System with G-Arm. In Bulgarian Иванова H., Ангиографска рентгенова система с G-рамо., Дозово натоварване на персонала, Медицински университет, Варна, ноември, eds., Dose load of Personnel, Medical University, Varna.

[2] Röntgen-Gamma, D. (2008) Technical Description and Operating Instructions. http://www.step-sensor.de/media/main/rgd_27091-manual_.pdf

[3] Pasciak, A.S., Bourgeois, A.C. and Jones, A.K. (2014) C-Arm Rotation as a Method for Reducing Peak Skin Dose in Interventional Cardiology. Open Heart, 1, Article ID: e000141.

https://www.ncbi.nlm.nih.gov/pmc/articles/PMC4281570/ https://doi.org/10.1136/openhrt-2014-000141

[4] Sadick, V., Reed, W., Collins, L., Sadick, N., Heard, R. and Robinson, J. (2010) Impact of Biplane versus Single-Plane Imaging on Radiation Dose, Contrast Load and Procedural Time in Coronary Angioplasty. Br J Radiol, 83, 379-394.

https://www.ncbi.nlm.nih.gov/pmc/articles/PMC3473578/ https://doi.org/10.1259/bjr/21696839

[5] Mavrikou, I., Kottou, S., Tsapaki, V. and Neofotistou, V. (2008) High Patient Doses in Interventional Cardiology Due to Physicians' Negligence: How Can They Be Prevented? Radiat Prot Dosimetry, 129, 67-70.

https://pubmed.ncbi.nlm.nih.gov/18337290/

https://doi.org/10.1093/rpd/ncn005

[6] Fornell, D., (2016) 5 Technologies to Reduce Cath Lab Radiation Exposure. Radiation Dose Management, August 09 2016, Dave Fornell.

https://www.dicardiology.com/article/5-technologies-reduce-cath-lab-radiation-exp osure

[7] Kesavachandran, C.N., Haamann, F. and Nienhaus, A. (2013) Radiation Exposure and Adverse Health Effects of Interventional Cardiology Staff. Environmental Contamination and Toxicology, 222, 73-91.

https://pubmed.ncbi.nlm.nih.gov/22990945/

https://doi.org/10.1007/978-1-4614-4717-7_2

[8] Moriña, D., Grellier, J., Carnicer, A., Pernot, E., Ryckx, N. and Cardis, E. (2016) Inter Cardio Risk: A Novel Online Tool for Estimating Doses of Ionising Radiation to Occupationally-Exposed Medical Staff and Their Associated Health Risks. Journal of Radiological Protection, 36, 561-578.

https://pubmed.ncbi.nlm.nih.gov/27460876/ https://doi.org/10.1088/0952-4746/36/3/561 